\title{
Efficient Halogen Lamp Daylight Simulator for Color Vision Examination
}

\author{
K. Samu ${ }^{1}$, A. Szakaly-Molnar ${ }^{2}$ \\ Department of Mechatronics, Optics and Engineering Informatics, Faculty of Mechanical Engineering, \\ Budapest University of Technology and Economics, Bertalan Lajos u. 4-6, D building 407, H-1111, Budapest, Hungary, \\ 1samuk@mogi.bme.hu, ${ }^{2}$ maniko@mogi.bme.hu
}

Recently there has been a growing interest in the selection of product colors for design engineering purposes and for quality control. The selection is generally based on color samples and the quality control is carried out with specific measurement instruments. In low quantity production it is common to avoid instrumental color measurement using human control personnel instead. For such subjective color judgment it is necessary to have standardized illumination that is usually produced by high cost daylight simulator lamps. Our aim was to build a cost effective daylight simulator with halogen incandescent light sources that can match the parameters (CCT, CRI, MI $_{\text {vis }}$ and Illumination) of the similar but more expensive products.

Keywords: Halogen lamp application, daylight simulator, light booths, A and D65 simulator

\section{INTRODUCTION}

QTANDARD LIGHT booths $[1,2,3]$ are regularly used $\checkmark$ in commercial applications, printing industry and in color vision testing. For cost reduction purposes usually cost effective light sources with non-continuous spectral power distribution are applied. Such sources (Fig.1) have low color rendering abilities (CRI) along with high metameric indices [4]

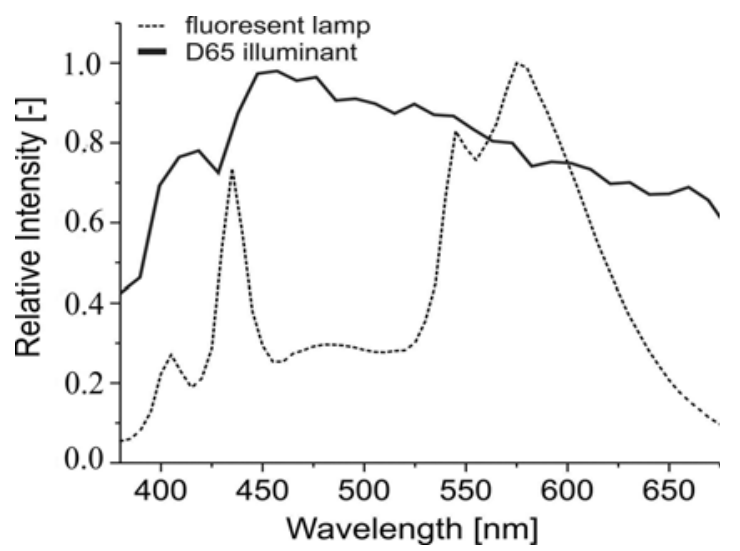

Fig.1. Spectral power-distribution of a low CRI fluorescent tube with spectral lines and the standard D65 continuous spectral power-distribution.

The application of such sources in production or in commercial applications can lead to several color matching problems and using them in color vision tests $[5,6]$ wrong diagnosis might be acquired. Several modern light sources with non-continuous spectral power distribution possess CRI values over 90; however, their spectral characteristics provide reduced color identification and discrimination abilities.

With the application of color samples in standardized light booths realistic color perception is induced, which provides the possibility for subjective quality control [7].

\section{Light BOOTH}

A general setup for light booths is represented in Fig.2. The instrument contains a standard light simulator consisting of one or more electronically controlled light sources along with specially selected color filters. The filters are plastic filters, because these are available on the market in big variation regarding their spectral transmission and their cost is one tenth of the price of the glass filters. A diffuser element is applied to provide homogeneous illumination. The illumination is built into a specially painted booth with its geometry designed for the purpose. The painting used is a diffuse grey, having equal spectral reflection in the visible range.

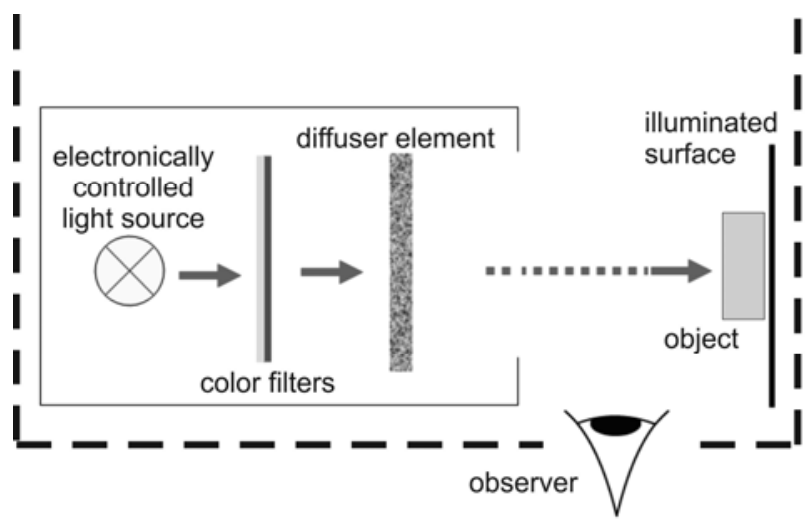

Fig.2. The setup of the light booth.

In addition to verifying the spectral power distribution, the quality of standard light booths is evaluated according to their color rendering properties (CRI) and metameric indices $\left(\mathrm{MI}_{\mathrm{vis}}\right)$.

The commercially available light booths usually have these parameters in the $80-95$ range for the CRI and $0-1.5$ for the $\mathrm{MI}_{\mathrm{vis}}$. As the constructed light booth will be applied for color vision tests it is evaluated for the visible wavelength range. Thus there is no need for the calculation of $\mathrm{MI}_{\text {luv }}$ ! 


\section{METHODS}

The structure of our light booth is displayed in Fig.3. The functional setup is very similar to that represented in Fig.2. The booth is made of block-boards painted with gloss-less neutral gray $(\rho \approx 20 \%)$.

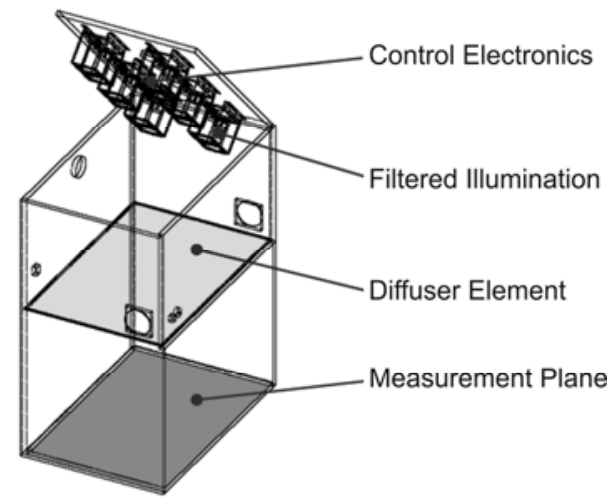

Fig.3. The structure of the light booth.

To provide standard D65 and A type illuminations we have applied six OSRAM DECOSTAR cold mirror halogen lamps with 4000 hours nominal lifetime [8]. We have positioned the lamps so that the illumination on the diffuser element (Fig.3.) would not create significant overlap (Fig.4.). The homogenous illumination was realized with the close positioning of the diffuser elements.

The lamps, the filters and the diffusers were placed into aluminum holders for both the D65 and the A simulators separately (Fig.4.). This way the significant amount of heat created by the lamps is conducted and the change of the lamps is made relatively easy. The cooling system is supported by two $25 \mathrm{~W}$ fans along with a grid controlling the air flow.

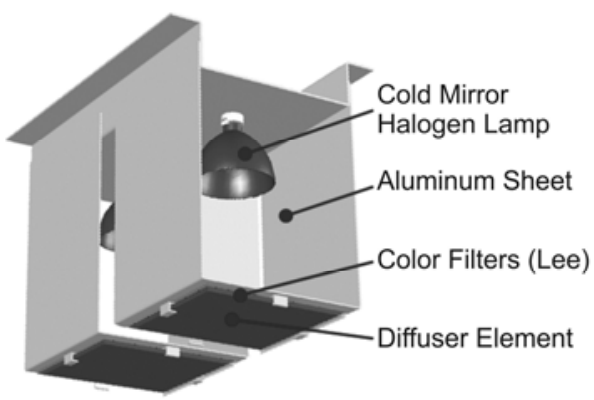

Fig.4. The module containing the halogen lamp with the filter and the diffuser.

Six such modules were applied onto the top of the light booth which can be opened when changing the lamps. The geometric design of the booth is made so that the measurement plane has homogeneous illumination. The external dimensions of the booth are 1200/1000/620 mm and the illuminated area is $650 / 960 / 600 \mathrm{~mm}$.

The diffuser and the color filters creating the $\mathrm{A}$ and the D65 standard illuminants are selected from the Lee catalogue. The selection of the filter combinations [9] is done by computerized simulation taking into account the differences between the spectral power distributions weighted with the color discrimination function, the color temperature, the CRI and MI values.

The input data of the simulation process were the transmission of the Lee color filters, transmission of the diffuser glass and the emission of the halogen lamp. The results with the different color filter combinations are displayed in Table1.

\begin{tabular}{|c|c|c|}
\hline Color filter combinations & $\begin{array}{c}\text { CCT } \\
(K)\end{array}$ & $\begin{array}{c}\text { Capital } \\
\text { Letters }\end{array}$ \\
\hline $\begin{array}{c}\text { type } 2 \text { color filter (1 layer } \\
+ \text { diffuser glass) }\end{array}$ & 3900 & $\mathrm{~B}$ \\
\hline $\begin{array}{c}\text { type } 2 \text { color filter (2 layers } \\
+ \text { diffuser glass) }\end{array}$ & 4300 & $\mathrm{C}$ \\
\hline $\begin{array}{c}\text { type } 2 \text { color filter (3 layers } \\
+ \text { diffuser glass) }\end{array}$ & 4900 & $\mathrm{E}$ \\
\hline $\begin{array}{c}\text { type } 2 \text { and } 4 \text { color filters (1 } \\
\text { layer +diffuser glass) }\end{array}$ & 6428 & $\mathrm{G}$ \\
\hline $\begin{array}{c}\text { halogen lamp without } \\
\text { color filter }\end{array}$ & 3350 & $\mathrm{~A}$ \\
\hline halogen + diffuser glass & 4730 & $\mathrm{D}$ \\
\hline $\begin{array}{c}\text { D65 (THIS IS THE } \\
\text { TARGET) }\end{array}$ & 6500 & $\mathrm{~F}$ \\
\hline
\end{tabular}

Table 1. Different color filter combinations with CCT.

Fig. 5 shows the realized CCT values with the different filter combinations having different spectral power distributions, see (Fig.6).

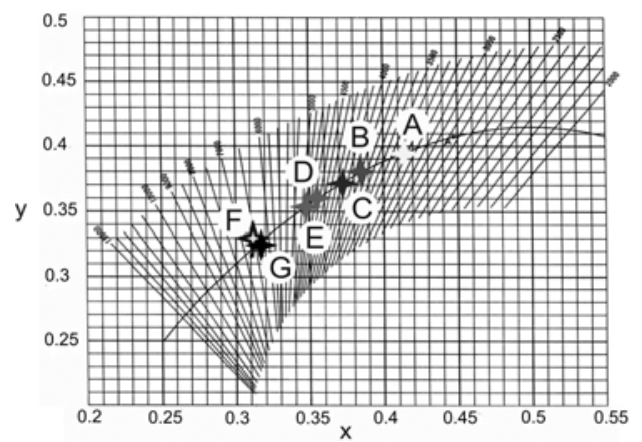

Fig.5. CCT of the combinations.

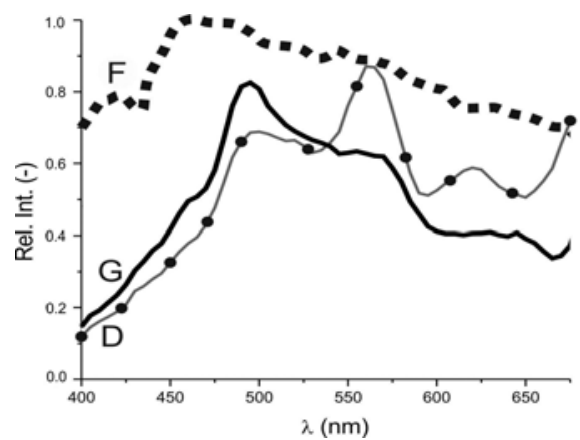

Fig.6. The spectral power distribution of the different color filter combinations. 
The switching of the halogen lamps (for both A and D65) along with the stability of their color temperature is controlled electronically (Fig.7). For cost effectiveness the lamps are powered with switching power supplies. To control the stability and settings of the color temperature we used a current generator adjustable by two potentiometers. These controls are used to compensate the changing emission characteristics of the aging lamps (recalibration is recommended every $1000 \mathrm{~h}$ ). The lamps were integrated after a 50 hour aging, and because of the demanding calibration of the instrument the 1000 hours is a compromised result by comparison with the 5000 hours lifetime of the applied lamp.

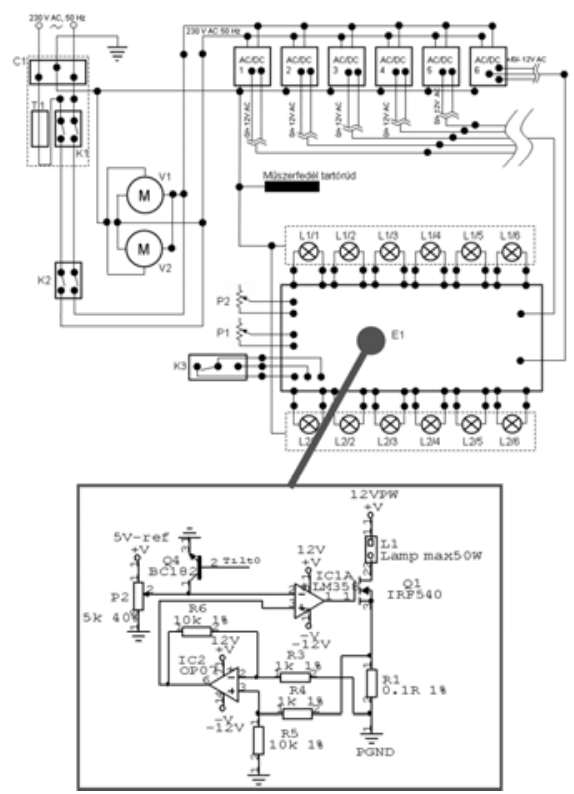

Fig.7. The module containing the halogen lamp with the filter and the diffuser.

The D65 illuminant was created with several (blue) Lee filters in different number of layers (Table 1.) and with the help of the current control. The A illuminant was obtained without any filter. The halogen lamp's color temperature was configured with the help of the current-generator.

Axonometric drawing of the assembled light booth is displayed in Fig.8.
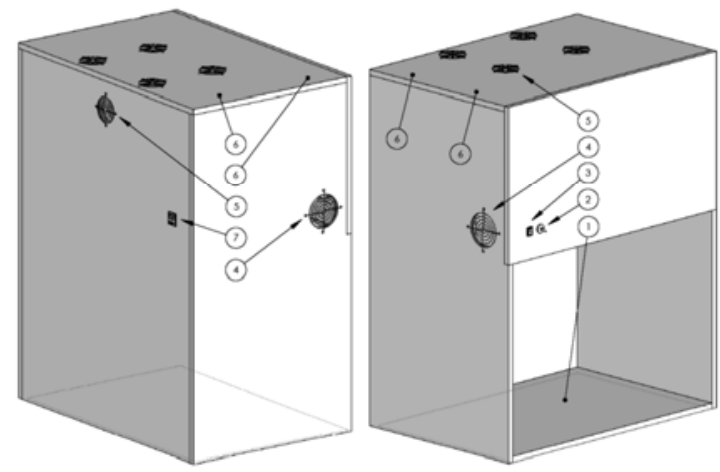

1. Illuminant surface + measurement plane 2. Color-temperature selection button (ADD6)
3. Power button 4. Fans - opening ( 2 pieces) 5 . Air - holes $(5$ pieces) 3. Power button 4. Fans - opening ( 2 pieces)
6. Cover - fixing screws $(2$ pieces $)$ 7. 3 poles $(5$ pieces $)$ power - socket + breaker + main

Fig.8. Front- and rear view of the standard light booth.

\section{MEASUREMENTS}

To verify the designed nominal parameters after assembling the standard light booth we have carried out several calibration tests. The designed nominal value for the illumination on the measurement plane was set to $1000 \pm$ $100 \mathrm{~lx}$. The illumination values provided by the standard D65 and A illuminants were measured in five points on the measurement plane (Fig.9). The 5 measured points were chosen near the edges and in the center of the booth where the color vision tests may be placed with high probability.

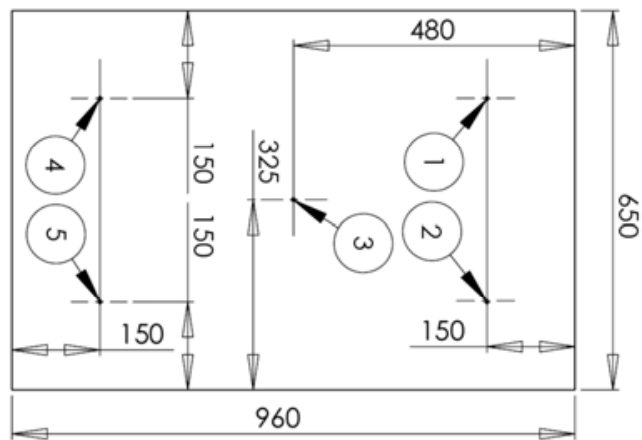

Fig.9. The measurement points.

The measured values in the 10 points ( 5 points for D65 and 5 points for the $\mathrm{A}$ ) were inside the $10 \%$ tolerance range for both simulators (Table 2.).

\begin{tabular}{|c|c|c|}
\hline $\begin{array}{c}\text { Measuring } \\
\text { point }\end{array}$ & $E(l x)$ & $\begin{array}{c}\text { Standard } \\
\text { Deviation }\end{array}$ \\
\hline 1 & 995 & 4.85 \\
\hline 2 & 962 & 6.87 \\
\hline 3 & 1010 & 7.98 \\
\hline 4 & 980 & 6.47 \\
\hline 5 & 954 & 5.69 \\
\hline 6 & 1012 & 4.12 \\
\hline 7 & 993 & 3.15 \\
\hline 8 & 1135 & 2.25 \\
\hline 9 & 1075 & 6.52 \\
\hline 10 & 1105 & 4.31 \\
\hline
\end{tabular}

Table 2. Illumination values in the five points on the measurement plane for the D65 (1-5) and the A (6-10) simulators respectively.

The following color differences were acquired for the calculation of the $\mathrm{MI}_{\mathrm{vis}}$ in the case of the D65 simulator (Table 3.).

\begin{tabular}{|c|c|c|c|c|c|}
\hline $\mathrm{i}$ & 1 & 2 & 3 & 4 & 5 \\
\hline$\Delta \mathrm{E}_{\mathrm{a}, \mathrm{b}} \mathrm{i}$ & 1.15 & 0.62 & 0.84 & 0.69 & 1.32 \\
\hline
\end{tabular}

Table 3. $\mathrm{MI}_{\mathrm{vis}}$ color differences in the case of the D65 simulator.

The spectral power distribution (spectral resolution was 5 $\mathrm{nm}$ ) and the color temperature were measured in measurement point No. 3. The standard deviations of the correlated color temperature values from 10 measurements are given in Table 4. The calculation of the CRI was according to the CIE 13.3 [10]. 


\begin{tabular}{|l|l|l|}
\hline $\begin{array}{l}\text { Type of } \\
\text { illumination }\end{array}$ & D65 & A \\
\hline CCT $[\mathrm{K}]$ & 6428 & 2913 \\
\hline CCTSD $[\mathrm{K}]$ & \pm 52.5 & $\begin{array}{l} \pm \\
33.4\end{array}$ \\
\hline CRI & 83 & 98 \\
\hline CRISD & \pm 0.25 & $\begin{array}{l} \pm \\
0.12\end{array}$ \\
\hline
\end{tabular}

Table 4. The CCT and CRI values.

$\mathrm{CCT}_{\mathrm{SD}}$ : standard deviation of the correlated color temperature at $99.5 \%$ confidence interval.

$\mathrm{CRI}_{\mathrm{SD}}$ : standard deviation of the color rendering index at 99.5\% confidence interval.

Fig. 10 shows the results of the spectral power distributions for the D65 and the A standard simulators.

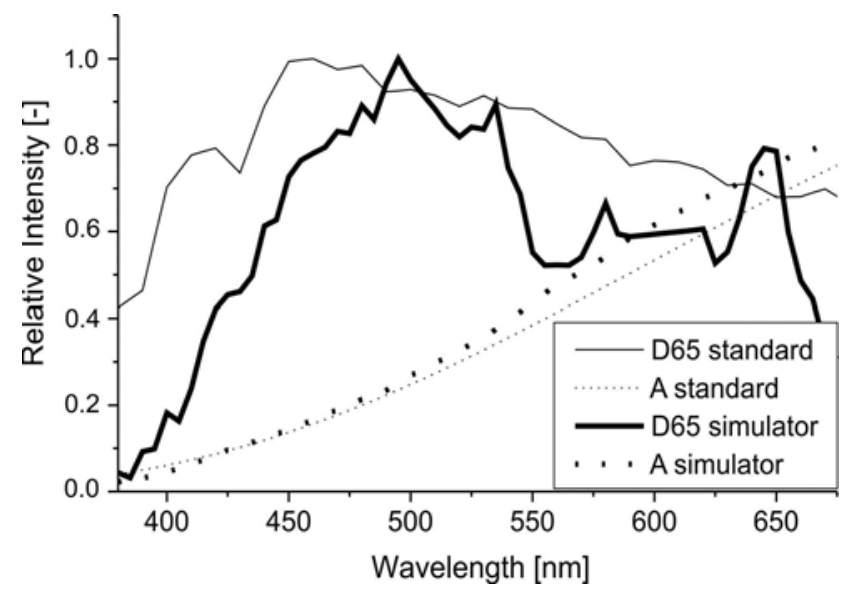

Fig.10. The spectral power distributions of the simulated and the standard illuminants (in the wavelength range of 400 to $675 \mathrm{~nm}$, in measurement point No. 3.).

The resulted spectral power distribution of our instrument shows significantly larger correlation with the standard illuminants than the commonly used daylight simulators. This might reduce metamerism in several cases and can induce the definition of new spectrum based value for the evaluation of daylight simulators.

Comparing the developed light booth with the commercial [11] one available at the MOGI Department of the BUTE we can conclude the following: the cost of the developed light booth reaches only one tenth of that of the commercial solution. The public procurement price of the industrially marketable light booth is about 4-5000€, while the developed one costs 450-500€. Certainly, the commercial device makes a wider range of applications possible, but for someone whom the examination under D65 and/or A standard illuminant is enough, the price of the developed light booth is more favorable. Although low-cost daylight simulator device for color vision testing (such as $\mathrm{C}$ Daylight $^{\mathrm{TM}}$ glasses [12]) already exists on the market, its usage may be uncertain as it depends on the light source used and other parameters of the illumination.
Fig.11 shows the comparison of the two light booths regarding the D65 standard illuminant and the calculated $\mathrm{MI}_{\mathrm{vis}}$ and CRI values.

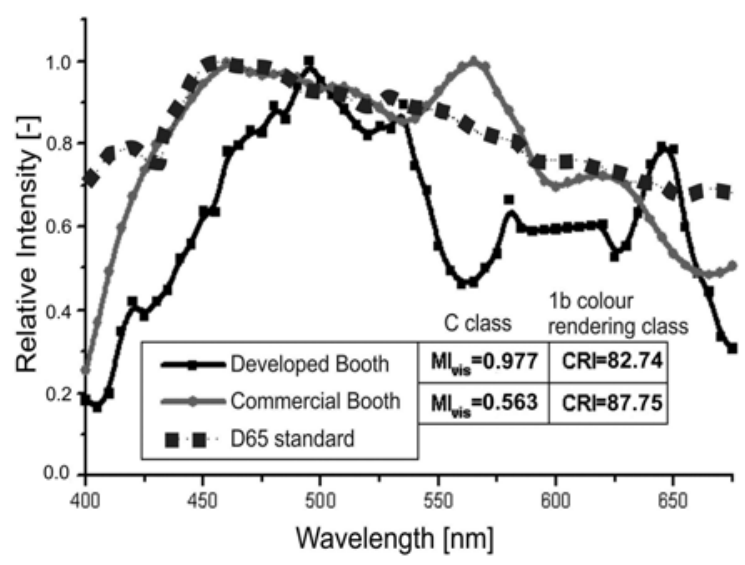

Fig.11. The spectral power distribution comparison of the light booths.

Based on the calculated values both light booths belong to the $1 \mathrm{~b}$ color rendering class and to the $\mathrm{C}$ class regarding the metameric index. Significantly different values were not experienced during the calculation of the color difference; therefore the $\mathrm{C}$ class classification in the visible spectrum is reasonable. This means that the two light booths have similar parameters and they belong to the same specification classes.

The commercial booths closely matching our developed daylight simulator in price (ours is still more cost effective) use typically fluorescent light sources with spectral power distributions similar to Fig. 1. Such booths are generally evaluated into 1 to 3 classes lower.

The commercially available booths having similar CRI and MI classifications as ours generally use filtered halogen incandescent light sources and have prices of at least one class higher than our self-developed daylight simulator. Thus we can say that our development combines low cost and higher classification.

\section{CONCLUSION}

With the application of halogen incandescent light sources the developed light booth reaches $1 \mathrm{~b}$ class in color rendering index and class $\mathrm{C}$ in metameric index. These values fulfill the criteria required for color-vision testing.

Beside the instrumental examination, the efficiency of the D65 simulation for the box can be demonstrated with color vision examination, as well. The Ishihara Test and the Farnsworth Munsell 100 Hue Test can be applied in D65 illumination, as the recommended examination conditions for these tests are "room in daylight, no direct sunlight" [13], and "C or average daylight" [14]. We examined 100 subjects for color vision deficiency with the D65 simulator and the results were matching perfectly to the results given by a Heidelberg Anomaloscope [15].

The use of commercially available cold-mirror halogen lamps and adequate filter combinations made it possible to build a light simulator with long lifetime, high stability and low cost. 
The developed equipment was compared with similar light booths, both on the basis of measurements (GretagMachbeth) and catalog data (Datacolor) [16]. The characteristic parameters (CCT, $\mathrm{MI}_{\mathrm{vis}}$ and $\mathrm{CRI}$ ) have fulfilled the requirements of the same category of both booths. Compared with fluorescent light booths, the CRI and the metameric indices of the equipment were better with category 1 or 2 . Thus the developed equipment has proven to be applicable in commercial, industrial and visual color testing tasks.

Further development will include an elapsed time display, controlled ventilation, more standard illuminants and builtin self-calibration along with inserting UV lightsources to be able to determine the $\mathrm{MI}_{\mathrm{luv}}$ too.

\section{REFERENCES}

[1] Koleske, J.V. (ed.) (1995). Color and Light, Paint and Coating Testing Manual (14th Ed.). Philadelphia: ASTM International, 447-457.

[2] Commission Internationale de l'Éclairage. (1999). A Method for Assessing the Quality of Daylight Simulators for Colorimetry. Technical Report CIE 051.2-1999.

[3] Datacolor - Lighting Booths, www.datacolor.com.

[4] Bass, M. (ed.) (2009). Handbook of Optics : Volume II, (3rd Ed.). McGraw-Hill Professional Publishing.

[5] Gyula, L. (1982). Színmérés. Budapest: Müszaki Könyvkiadó. (in Hungarian)
[6] Omar, R. (2005). Color vision deficiency in retinitis pigmentosa. International Congress Series, 1282, 684-688.

[7] Dain, S.J. (1998). Daylight simulators and color vision tests. Ophthalmic and Physiological Optics, 18 (6), 540-544.

[8] Osram Cold Mirror Halogen Lamp. www.osram.com.

[9] Lee Color Filters. www.leefilters.com.

[10] Commission Internationale de l'Éclairage. (1995). Method of Measuring and Specifying Color Rendering Properties of Light Sources. Technical Report CIE 013.3-1995.

[11] X-Rite Spectralight III Color Viewing Booth. www.dtgweb.com.

[12] Moreland, J.D., Westland, S. (2001). Efficacy of a color conversion filter in color-vision testing. Color: Research and Application, 26 (8), S258-S260.

[13] Farnsworth, D. (1943). The Farnsworth-Munsell 100 hue-test. Journal of the Optical Society of America, 33 (10), 568-574.

[14] Ishihara, S. (1996) The Series of Plates Designed as Test for Colour-Deficiency. Tokyo: Kanehara \& Co.

[15] Wenzel, K., Ladunga, K., Samu, K., Langer, I., Szőke, F. (2011) Pseudo-isochromatic plates for measuring the ability to discriminate colours. In The 21st Symposium of the International Colour Vision Society. Kongsberg, Norway.

[16] Light Booths. www.colorhq.com.

Received July 6, 2011. Accepted October 21, 2011. 